\title{
PERANCANGAN SISTEM INFORMASI MEDIA KOMUNIKASI BERBASIS ANDROID
}

\author{
Reni Haerani ${ }^{1}$, R Dewi Mutia Farida ${ }^{2}$ \\ ${ }^{1,2}$ Program Studi Manajemen Informatika Politeknik PGRI Banten \\ Jl.Raya Cilegon - Serang KM.12 Serdang Kramatwatu Serang - Banten 42161 \\ ${ }^{1}$ renihaerani@politeknikpgribanten.ac.id, \\ ${ }^{2}$ d3wi_lp3i@yahoo.co.id
}

\begin{abstract}
Abstrak- Sistem Informasi Media Komunikasi merupakan sebuah media komunikasi pendidikan yang membantu Politeknik PGRI Banten dalam menjalin komunikasi antara berbagai pihak terkait didalam proses perkuliahan di Politeknik PGRI Banten. Sistem Informasi Media Komunikasi yang terintegrasi dengan data yang dimiliki ini mempercepat proses informasi yang awalnya terjadi secara konvensional menjadi lebih modern berbasis android, sehingga berita atau informasi yang terjadi menjadi lebih mudah tersampaikan kepada mahasiswa dan dosen. Teknologi yang digunakan dalam mengembangkan sistem informasi media komunikasi menggunakan bahasa pemrograman JavaScript dan MySQL (untuk servis database) yang digabungkan dengan pemrograman Android. Dalam pengembangan sistem ini, mengembangkan sistem dengan menggunakan tahapan waterfall yang memiliki beberapa tahapan. Diantaranya Analisa kebutuhan, Desain, Testing, Implementasi serta Perawatan dalam memperbaiki kesalahan yang tidak ditemukan pada langkah sebelumnya. Metode yang digunakan adalah model OOAD (Object Oriented Analysis dan Design) dimana dasar pembuatannya adalah objek yang merupakan kombinasi antara struktur data dan perilaku dalam satu entitas. Penelitian ini bertujuan untuk memberikan informasi secara real time dan informasi yang bersifat penting dapat tersampaikan dalam satu waktu bersamaan saat proses di sistem media komunikasi Politeknik PGRI Banten. Penelitian menghasilkan sebuah sistem informasi media komunikasi yang dapat digunakan pihak Politeknik PGRI Banten kapanpun dan dimanapun secara cepat, efektif dan efisien dengan syarat terhubung dengan jaringan internet.
\end{abstract}

Kata Kunci : Sistem Informasi, Media Komunikasi, Android, Waterfall, OOAD

\section{PENDAHULUAN}

Komunikasi memegang peranan terpenting dalam menyatukan berbagai aktivitas dalam kehidupan. Komunikasi menjembatani proses dalam pertukaran informasi maupun pengetahuan antar personal maupun antar masyarakat sehingga terjadi interaksi diantara mereka. Agar komunikasi interpersonal berjalan lancar dan mendatangkan hasil yang diterapkan, baik pemberi maupun penerima pesan perlu memiliki kemampuan dan komunikasi interpersonal yang diperlukan [1]. Komunikasi pada masa kini, terjadi baik secara langsung maupun menggunakan media komunikasi. Pemanfaatan media komunikasi membantu proses pertukaran informasi sehingga pesan atau informasi dapat dengan cepat tersampaikan. Di dunia pendidikan, komunikasi juga memiliki peranan yang sangat penting. Komunikasi membantu staf akademik dan dosen menyampaikan pengetahuan dan informasi kepada para mahasiswa. Namun proses komunikasi yang terjadi masih kurang efisien dan efektif karena masih mengandalkan komunikasi secara langsung. Adapun pemanfaatan media komunikasi masih kurang mendapat perhatian khusus. Padahal sebenarnya, pemanfaatan media komunikasi sudah disadari dapat membantu penyampaian pesan atau informasi secara efektif dan akurat.

Politeknik PGRI Banten adalah salah satu Perguruan Tinggi Swasta vokasi (D3) di Kabupaten Serang berdiri sejak tahun 2003 yang memiliki 3 program studi yaitu : Teknik Mesin, , Teknik Elektronika dan Manajemen Informatika. Secara garis besar informasi harus dapat diolah, dikembangkan dan di bagikan kepada mahasiswanya. Oleh sebab itu Politeknik PGRI Banten harus mempunyai sistem media komunikasi untuk menunjang penyebaran informasi seputar Politeknik PGRI Banten kepada mahasiswa, dosen dan pihak-pihak terkait. 
Sistem media komunikasi di politeknik PGRI Banten berbentuk display monitor berbagi informasi belum digunakan. Tetapi sudah menggunakan website, hanya saja belum mencukupi untuk memberikan informasi langsung secara realtime kepada pihak-pihak terkait dalam internal institusi.

Penelitian ini bertujuan memberikan informasi secara real time dan informasi yang bersifat penting dapat tersampaikan dalam satu waktu bersamaan saat proses di sistem media komunikasi Politeknik PGRI Banten. Sistem media komunikasi menggunakan program berbasis Android agar lebih memudahkan layanan informasi kepada mahasiswa, dosen dan pihak-pihak terkait secara efisien dan efektif.

\section{Perancangan Sistem}

Perancangan Sistem adalah sekumpulan aktivitas yang menggambarkan secara rinci bagaimana sistem akan berjalan [2]. Hal itu bertujuan untuk menghasilkan produk perangkat lunak yang sesuai dengan kebutuhan user.Proses mengidentifikasi proses-proses data yang diperlukan oleh sistem baru. Jika sistem yang dirancang adalah sistem berbasis komputer, perancangan dapat menyertakan spesifikasi jenis peralatan yang digunakan [3]. Kegiatan yang memiliki tujuan untuk mendesain sistem baru yang dapat menyelesaikan masalah-masalah yang dihadapi yang diperoleh dari pemilihan alternatif sistem yang terbaik [4].

\section{Media Komunikasi}

Media Komunikasi adalah suatu alat yang memindahkan informasi (pesan) dari sumber kepada penerima[5]. Sebagai sebuah sarana yang dipergunakan untuk memproduksi, reproduksi mengolah dan mendistribusikan dalam menyampaikan sebuah informasi.Alat-alat teknologi yang meningkatkan kemampuan alamiah manusia untuk menciptakan, mentransmisikan, menerima serta memproses pesan-pesan komunikasi baik secara virtual, terdengar, tercium, terperanga, terasa atau tersentuh [6]. Media komunikasi sangat berperan penting bagi kehidupan masyarakat [7]. Sebuah media komunikasi adalah sebuah perantara dalam menyampaikan sebuah informasi dari komunikator kepada komunikan yang bertujuan agar efisien dalam menyebarkan informasi atau pesan.

\section{Android}

Android merupakan sebuah sistem operasi berbasis Linux yang bersifat terbuka (open source) dan dirancang untuk perangkat smartphone dan komputer tablet [8]. Android juga dapat dikembangkan oleh setiap programmer yang memiliki kemampuan dibidang system operasi linux dan bahasa pemrograman Java. Android juga menyediakan platform terbuka bagi para programmer untuk mengembangkan aplikasi yang akan digunakan untuk bermacam peranti bergerak [9].

\section{JavaScript}

Merupakan bahasa skript populer yang dipakai untuk menciptakan halaman Web yang dapat berinteraksi dengan pengguna dan dapat merespon event yang terjadi pada halaman. JavaScript merupakan perekat yang menyatukan halaman-halaman Web [10].

\section{METODOLOGI PENELITIAN}

Metodologi yang digunakan dalam penelitian ini adalah metode pengembangan perangkat lunak waterfall. Model ini memungkinkan pemecahan misi pengembangan yang rumit menjadi beberapa langkah logis. Beberapa tahapan dalam metode penelitian ini adalah analisa kebutuhan dengan cara melakukan penelitian pada sistem yang masih berjalan. Tahap menyiapkan desain yang dibutuhkan, tahap merancang desain sistem yang dibuat sesuai kebutuhan, tahap melakukan pengujian pada program yang telah dibuat untuk memastikan program aplikasi berjalan dengan baik kemudian melakukan penerpan pada perangkat lunak atau program yang telah dibuat dan diuji serta melakukan pemeliharaan.

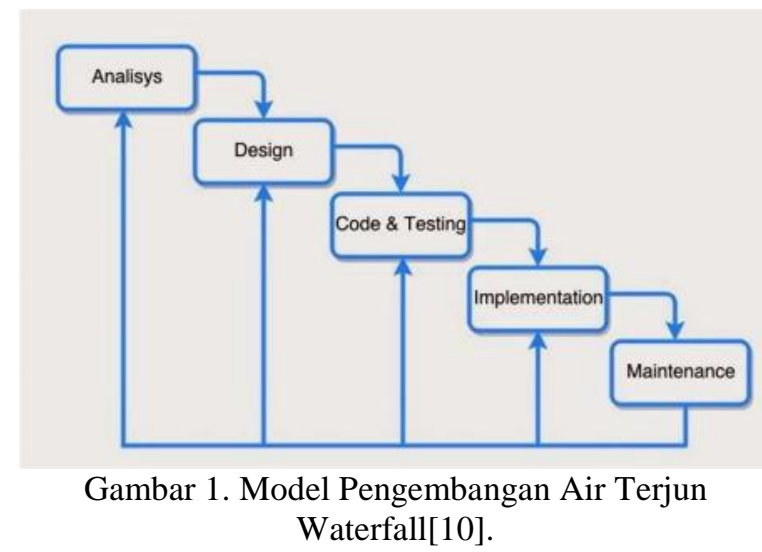

III. HASIL DAN PEMBAHASAN

Hasil dan pembahasan akan diuraikan mengenai hasil perancangan sistem, implementasi serta keluaran dari penelitian.

\section{A. Perancangan Sistem}

Sistem yang dirancang merupakan usulan perancangan sistem untuk memperbaiki sistem media komunikasi yang sedang berjalan sebelumnya, sistem ini memiliki peranan yang sangat penting dalam penyebaran informasi yang bersifat penting bagi mahasiswa, dosen, dan pihak terkait.

\section{Flowmap Media Komunikasi yang Diusulkan}

Merupakan gambaran pergerakan proses yang menampilkan serta mendeskripsikan langkah-langkah unit kerja beserta urutannya dengan menghubungkan masingmasing langkah proses menggunakan tanda panah, sekaligus menggambarkan arus dari dokumen. 


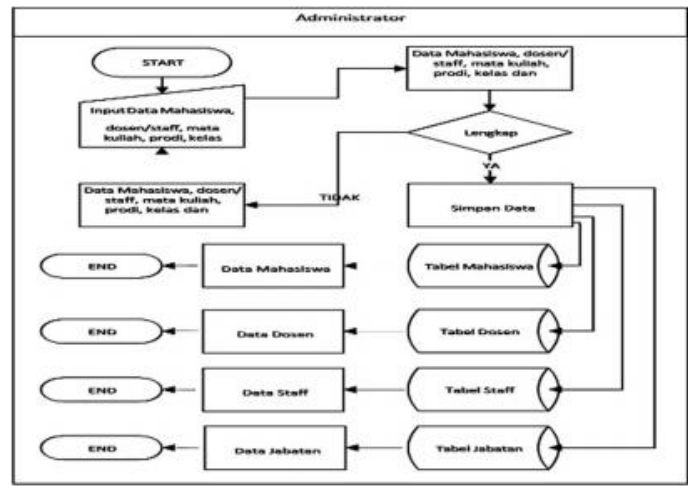

Gambar 2. Flowmap Proses Input Data Master

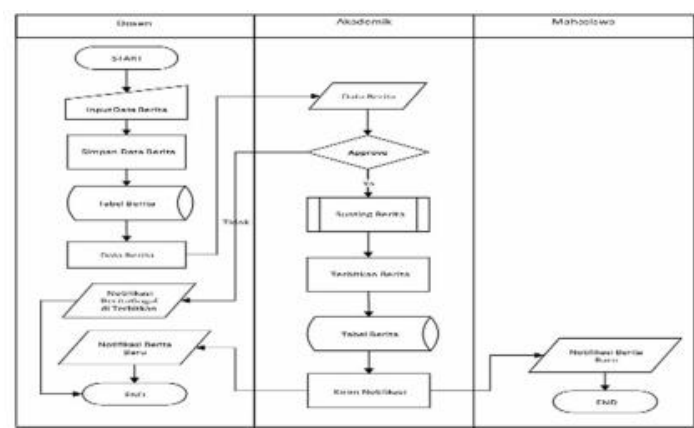

Gambar 3. Flowmap proses membuat berita untuk dosen

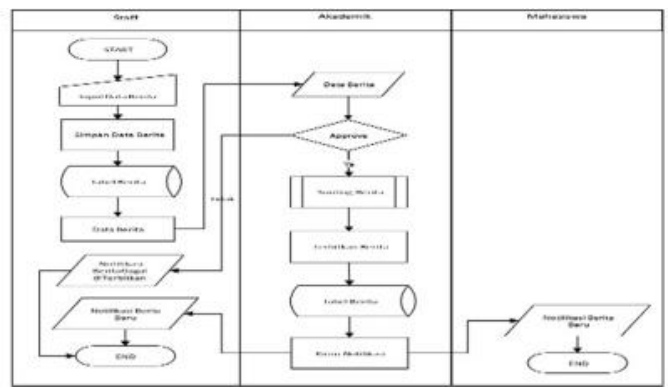

Gambar 4. Flowmap proses membuat berita untuk Staff

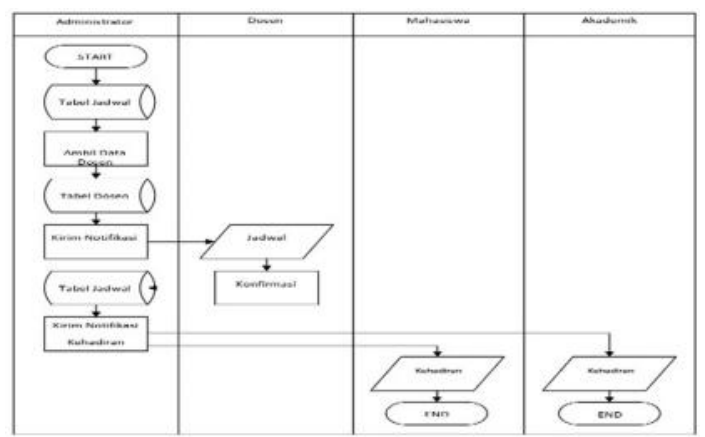

Gambar 5. Flowmap proses konfirmasi kehadiran dosen

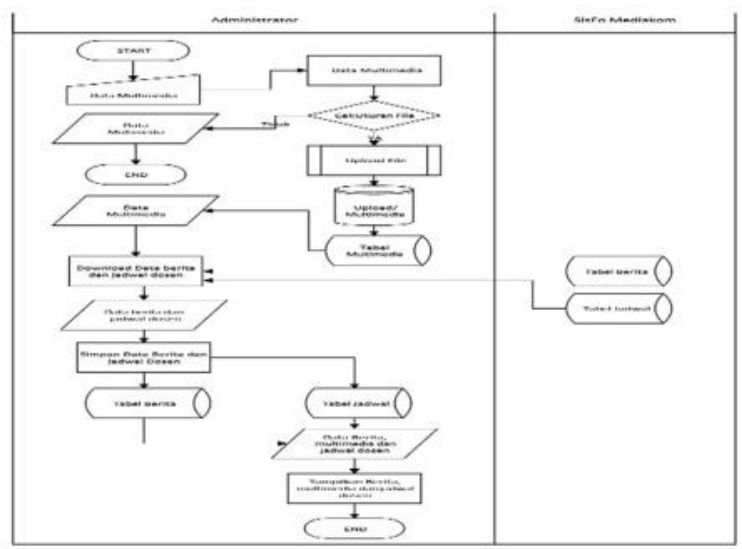

Gambar 6. Flowmap proses Display Monitor

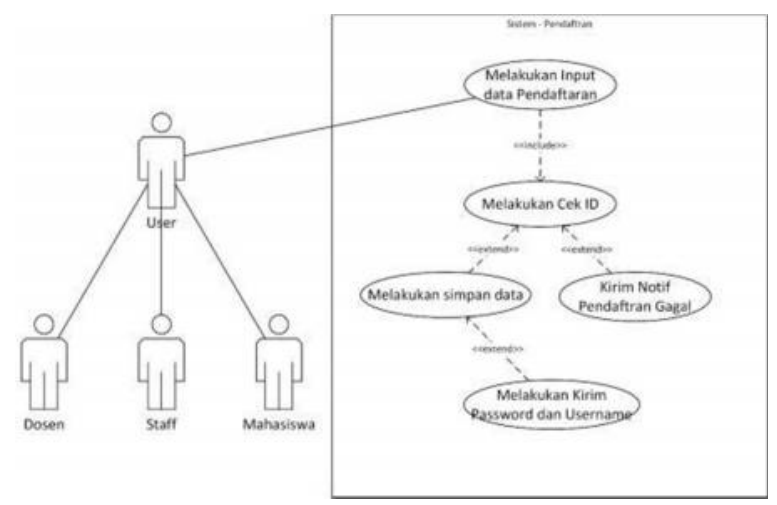

Gambar 7. Use Case Proses Pendaftaran

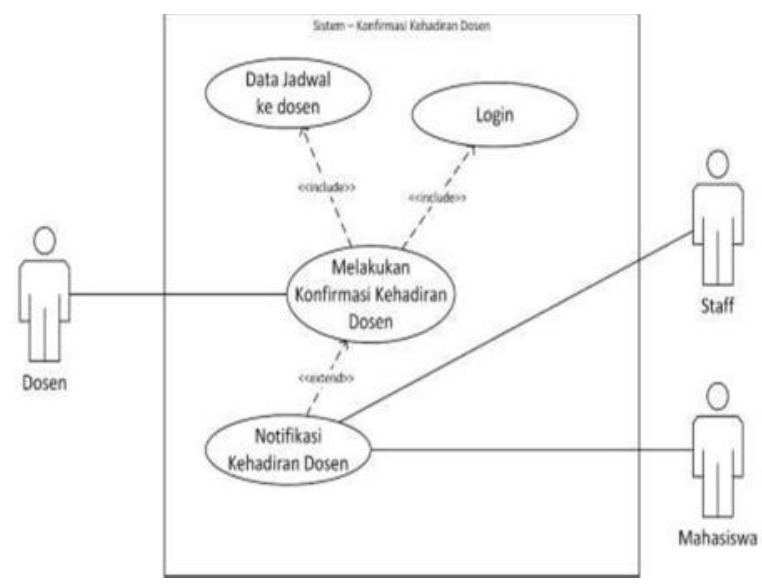

Gambar 8. Use Case Proses Konfirmasi Kehadiran Dosen 


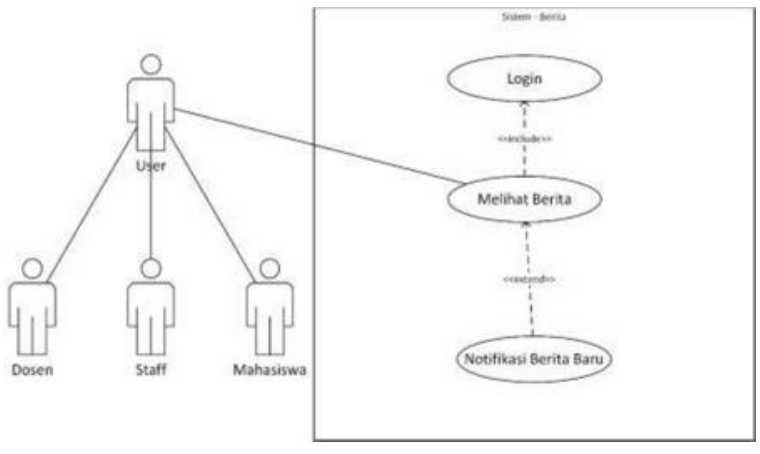

Gambar 9. Use Case Proses Sistem Berita

\section{Diagram Konteks Media Komunikasi yang} diusulkan

Merupakan Alat untuk struktur analisa yang menggambarkan sistem secara umum.Sistem informasi yang dibuat akan menghasilkan sumber informasi yang dibutuhkan dan tujuan informasi yang dihasilkan.

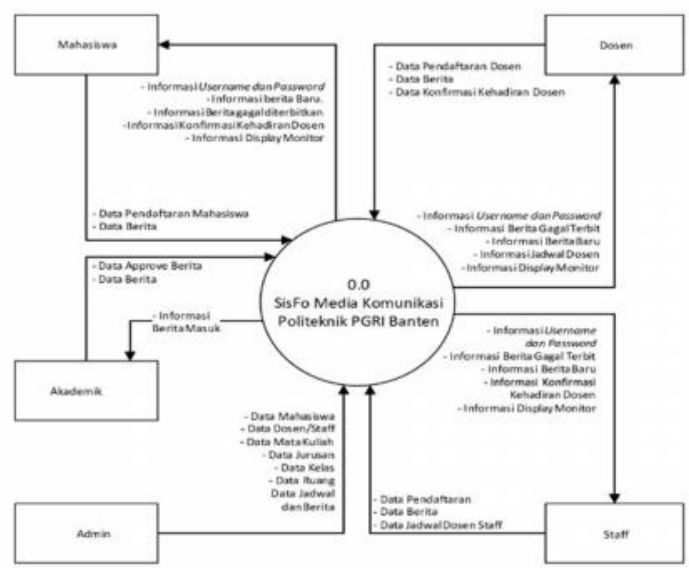

Gambar 10. Diagram Konteks

\section{Kamus Data}

Kamus data merupakan katalog fakta tentang data dan kebutuhan informasi. Dengan menggunakan kamus data, analisa sistem dapat mendefinisikan aliran data yang ada di sistem dengan lengkap.
Tabel 1. Kamus Data

\begin{tabular}{|c|l|l|}
\hline 1 & $\begin{array}{l}\text { Tabel Dosen } \\
\text { Staff }\end{array}$ & $\begin{array}{l}\text { Dosen_Staff } \\
\text { \{id_dosen, nama, jk, agama, tempat_lahir, tanggal_lahir, } \\
\text { alamat, tlp, email, status, nidn, gelar, \} }\end{array}$ \\
\hline 2 & Tabel User & $\begin{array}{l}\text { sys_user } \\
\text { \{user_id, username, password, email, status, level, } \\
\text { token, app_id, id_dosen, npm\} }\end{array}$ \\
\hline 3 & $\begin{array}{l}\text { Tabel } \\
\text { Mahasiswa }\end{array}$ & $\begin{array}{l}\text { mahasiswa } \\
\text { \{npm, nama, agama, jk, tempat_lahir, tanggal_lahir, tlp, } \\
\text { alamat, email, tgl_masuk, tgl_keluar, status, jurusan\} }\end{array}$ \\
\hline 4 & Tabel Berita & $\begin{array}{l}\text { Berita } \\
\text { \{id_berita, judul, berita, img, user_id, status, tgl\} }\end{array}$ \\
\hline 5 & Tabel Jadwal & $\begin{array}{l}\text { Jadwal } \\
\text { \{id_jadwal, jam_masuk, jam_keluar, tanggal, pertemuan, } \\
\text { jurusan, kelas, ruang, mk, semester, id_dosen\} }\end{array}$ \\
\hline
\end{tabular}

B. Implementasi Sistem Informasi

Pada tahapan implementasi,, rancangan dan kode program yang telah dibuat dioperasikan menjadi sebuah sistem informasi media komunikasi pada Politeknik PGRI Banten.

\section{Menu Login}

Berfungsi untuk memasukkan userid dan Password sebelum mengakses aplikasi media komunikasi dan dapat masuk ke halaman utama untuk user yang sudah terdaftar. Tampilan halaman login sebagai berikut :

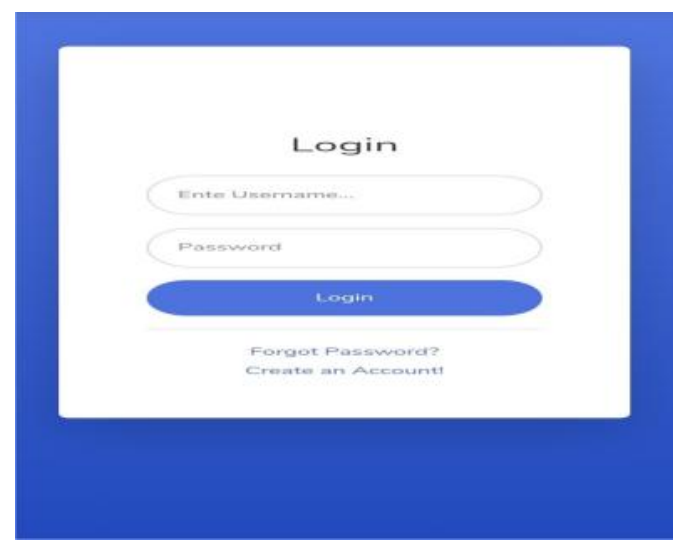

Gambar 11. Tampilan Menu Login Sistem

2. Menu Berita

Halaman Menu berita ini menampilkan data yang sudah di posting atau diterbitkan. Adapun tampilan menu berita sebagai berikut : 


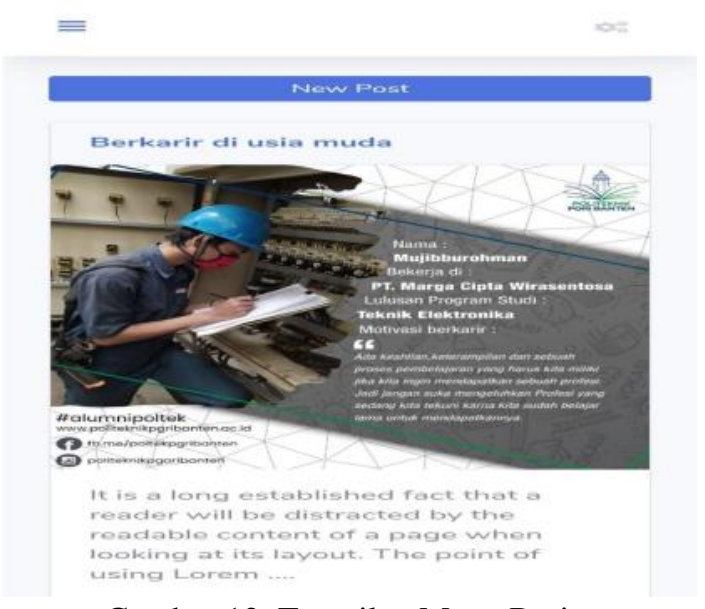

Gambar 12. Tampilan Menu Berita

3. Halaman Utama

Tampilan Halaman Utama berfungsi untuk menampilkan menu utama pada aplikasi berupa pilihan menu-menu yang dapat dilakukan oleh user sesuai dengan akses pengguna. Adapun tampilan Halaman Utama sebagai berikut :
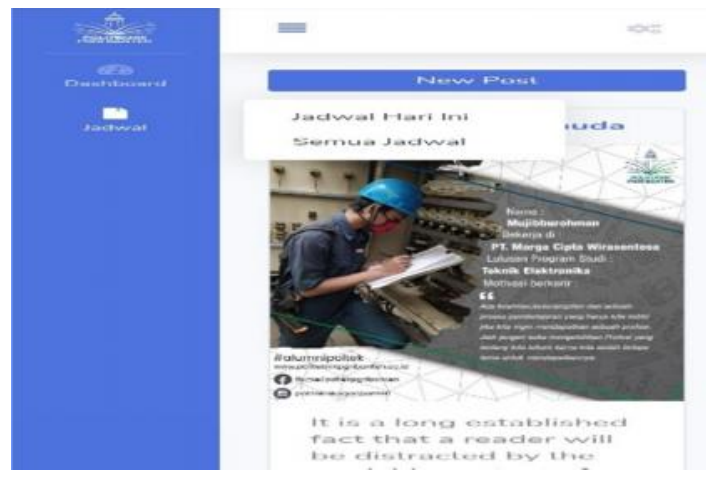

Gambar 13. Tampilan Halaman Utama

4. Menu Registrasi

Menu Registrasi merupakan halaman para pengguna untuk mendaftar dan mendapatkan userid dan Password dengan persetujuan admin. Tampilan Menu Registrasi sebagai berikut :

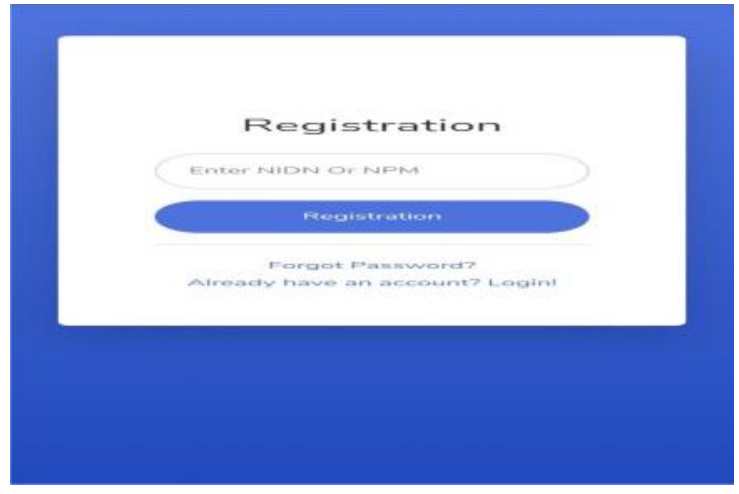

Gambar 14. Tampilan Menu Registrasi

5. Input Data Dosen

Halaman Input Data Dosen berfungsi untuk memasukkan data dosen dan staff, dapat disimpan pada database, data yang telah diinput akan secara otomatis tampil pada menu master dosen dan staff. Adapun tampilan Input Data Dosen sebagai berikut :

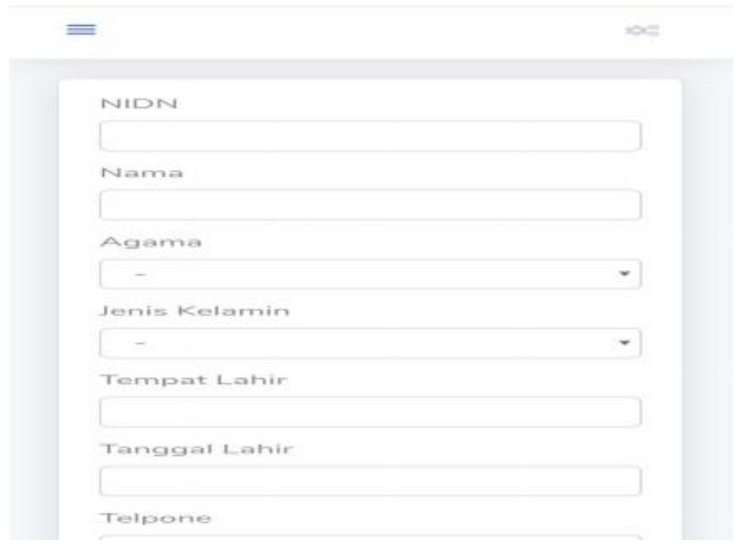

Gambar 15. Tampilan Input Data Dosen

\section{Data Dosen}

Halaman Data Dosen ini menampilkan data dosen yang sudah dibuat. Tampilan data dosen sebagai berikut : 


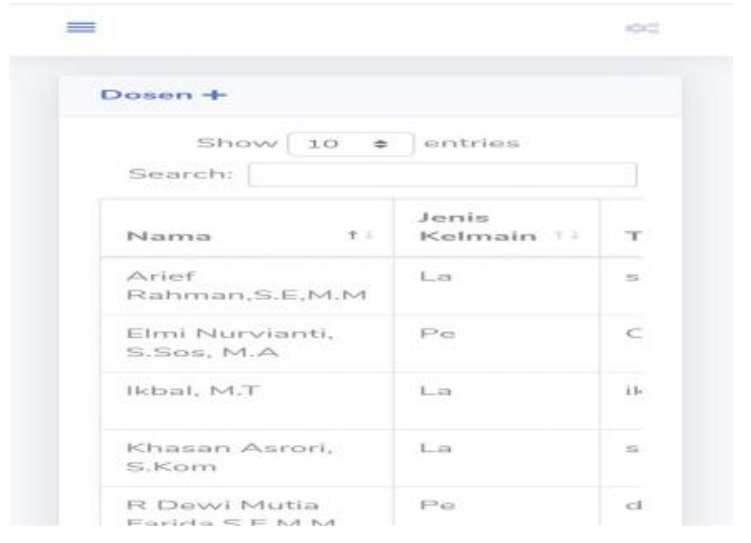

Gambar 16. Tampilan Data Dosen

7. Input Jadwal Dosen

Halaman Input Jadwal Dosen ini untuk memasukkan data jadwal dosen dan dapat disimpan pada database. Tampilan Input Jadwal Dosen sebagai berikut :

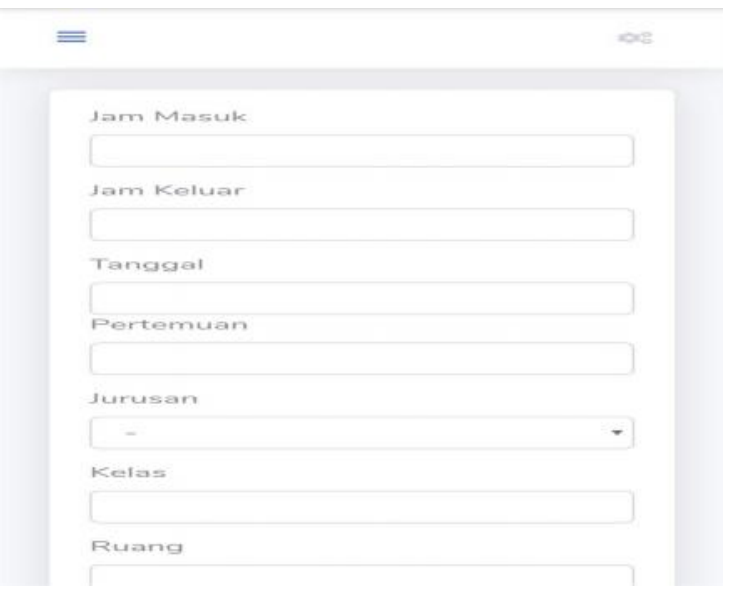

Gambar 17. Tampilan Input Jadwal Dosen

8. Input Data Mahasiswa

Halaman Input Data Mahasiswa ini untuk memasukkan data mahasiswa dan dapat disimpan pada database. Tampilan Input Data Mahasiswa sebagai berikut :

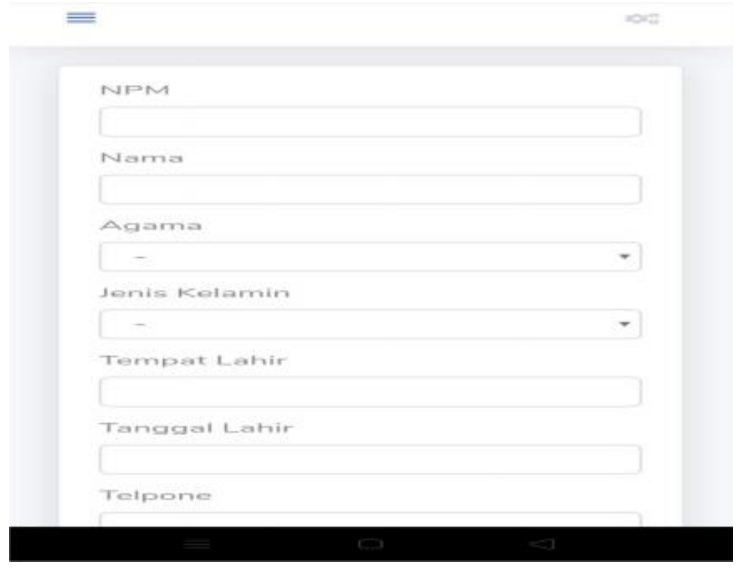

Gambar 18. Tampilan Input Data Mahasiswa

9. Input Username

Halaman Input Username berfungsi untuk menambahkan user baru. Tampilan Input Username sebagai berikut :

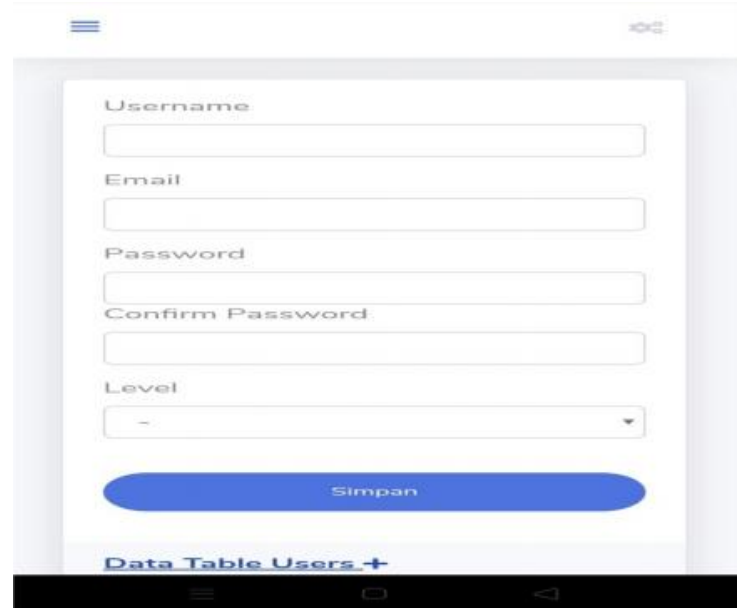

Gambar 19. Tampilan Input Username

IV. KESIMPULAN

Berdasarkan hasil kegiatan penelitian yang dilakukan dapat diambil kesimpulan sebagai berikut :

a. Dengan sistem informasi media komunikasi berbasis android akan mempermudah semua pihak di Politeknik PGRI Banten dapat saling bertukar informasi dan pesan kapanpun dan dimanapun.

b. Penggunaan media komunikasi berbasis android ini, juga dapat membantu proses belajar mengajar dalam menyampaikan informasi kepada mahasiswa.

c. Sistem informasi media komunikasi ini dapat digunakan sebagai sarana pendidikan karena cepat, efektif dan efisien. 


\section{UCAPAN TERIMAKASIH}

Terimakasih disampaikan kepada RISTEK-BRIN, Lembaga Layanan Pendidikan Tinggi Wilayah IV yang telah mendanai Penelitian Dosen Pemula (PDP) tahun anggaran 2020, dan seluruh Civitas Akademik Politeknik PGRI Banten yang telah banyak membantu dalam hal penyediaan data pendukung penelitian.

\section{REFERENSI}

[1] Agus M.Hardjana, (2003). Komunikasi Intrapersonal \& Interpersonal, Yogyakarta, Penerbit Kanisius, 90

[2] Al-Bahra Bin Ladjamudin,(2005). "Analisis \& Desain Sistem Informasi," in Analisis \& Desain Sistem Informasi., 2005, p. 39.

[3] Brent D Ruben,(1992). Communication and Human Behaviour, Prentice Hall,

[4] Dhavan V. Shah, Jack M. McLeod, So-Hyang Yoon. (2001). Communication, Contex, and Community : An Exploration of Print, Broadcast, and Internet Influences. 2001, Vol.28, issue : 4, p.464-506.

[5] Efy Widyawati, Ari Kurniawan, (2016) "Rancang Bangun Aplikasi Kependudukan Berbasis Web Di

Desa Kedungrejo Waru-Sidoarjo”, Jurnal Manajemen Informatika, Volume 6, Nomor 1, 2016, 172

[6] Haerani, reni; robiyanto, robiyanto. (2019) sistem informasi pengolahan data nilai siswa berbasis web. JSiI (Jurnal Sistem Informasi), 2019, 6.2: 103-109. http://e-

jurnal.lppmunsera.org/index.php/jsii/article/view/15 50

[7] I. Sommerville, (2011). Software Engineering Ninth Edition, Boston : Person Education, 2011.

[8] Muhamad Son Muarie, (2014). "Sistem Informasi Perpustakaan SMP Negeri 5 Palembang Menggunakan PHP dan MySQL", Jurnal Teknik Informatika Politeknik Sekayu, Volume 1, Nomor 1, September 2014, 29

[9] Kusrini. (2013). Tuntunan Praktis Membangun Sistem Informasi Akuntansi dengan Visual Basic dan Microsoft SQL Server, Andi, Yogyakarta, 2013.

[10] Mulyani, Sri. (2016). Metode Analisis dan Perancangan Sistem, Abdi Sistematika.,Bandung, 2016.

[11] Muslihudin, Muhamad dan Oktafianto. (2016). Analisis dan perancangan sistem informasi menggunakan model terstruktural dan UML, Andi, Yogyakarta, 2016.
[12] Priyadi, Yudi.(2014). Kolaborasi SQL dan ERD dalam implementasi Database, Andi, Yogyakarta, 2014.

[13] R.H Sianipar. (2017). Dasar Pemrograman JavaScript, langkah demi langkah. Penerbit ANDI, 2017.

[14] Salbino, Sherief. (2014) Buku Pintar Gadget Android untuk Pemula, Kunci Komunikasi, Jakarta, 2014.

[15] Satjinger, Jackson dan Burd (2012), Perancangan Sistem, 2012 hal 5

[16] Teori Komunikasi, Theorie of Human Communication; Stephen W. Littlejohn dan Karen A Foss, Penerbit Salemba

[17] Utami, Endah Tri. (2011). Kupas Tuntas Android Dari Nol Sampai Bisa. Jakarta : Gudang Ilmu, 2011

[18] Wibawanto, Wandah. (2017). Desain dan Pemrograman Multimedia Pembelajaran Interaktif. Jember: Cerdas Ulet Kreatif.

[19] Winarto Edi, Ali Zaki, (2012) Smit Dev Community. Membuat Aplikasi Android Untuk Pemula. Jakarta : Kompas Gramedia Building 2012. 